\title{
Isolated DHEAS elevation causing Hirsutism and Oligomenorrhea- A case report
}

Ehtasham Ahmad ${ }^{1}$, Kashif Hafeez ${ }^{1}$, Muhammad Fahad Arshad ${ }^{2}$, Jimboy Isuga $^{1}$

1. Tunbridge Wells Hospital

2. Sheffield Teaching Hospitals

\section{INTRODUCTION}

Hirsutism is an endocrine condition affecting females with growth of unwanted, malepattern hair secondary to excess androgen activity. The most common cause of hirsutism in females is PCOS (Polycystic ovarian syndrome). Other causes are fairly rare including adrenal and ovarian androgen producing tumours. In $3 \%$ of cases no cause of hirsutism is found and these are termed idiopathic ${ }^{1}$.

\section{THE CASE}

We describe a unique case of a 22-year-old presenting with elevated DHEAS levels with no source identified on imaging. She achieved menarche at age of 13 followed by irregular scanty menstrual cycles and development of excess hair on her back, chin, chest, abdomen shoulders and inner thighs. Her mother and sister also have hirsutism. Initially she was treated with OCP which did not help with the symptoms. She never complained of acne. She has never been sexually active.

On examination, she had marked hirsutism of the areas mentioned above. Her breast development was at Tanner stage 4. BMI of 27 and BP was 133/77.

\section{LAB INVESTIGATIONS}

Her biochemistry showed elevated DHEAS of $16.6 \mathrm{umol} / \mathrm{L}$ with serum Androstenedione of $5.8 \mathrm{nmols} / \mathrm{L}$ and normal serum testosterone of $1.5 \mathrm{nmol} / \mathrm{L}$, rest of the endocrine work up including electrolytes, ODST for Cushing's, 17-OH progesterone for $\mathrm{CAH}$, serum prolactin $\mathrm{LH}, \mathrm{FSH}$, progesterone, TFTs, 24 hours urinary steroid profile were all unremarkable. Serum ACTH was $16 \mathrm{ng} / \mathrm{L}$. 48-hour low dose dexamethasone test suppressed the DHEAS to 4.7umol/I consistent with normal dexamethasone suppression. Similarly, a repeat 24-hour urinary steroid profile following 48hour dexamethasone suppression test was also consistent with dexamethasone suppression with no positive evidence for autonomous production of adrenal androgens. This excluded ectopic or autonomous source of elevated DHEAS.

\begin{tabular}{|c|c|c|}
\hline Investigations & Results & Normal ranges \\
\hline DHEAS & $16.6 \mathrm{umol} / \mathrm{L}$ & $0.9-11.6 \mathrm{umol} / \mathrm{L}$ \\
\hline Androstenedione & $5.8 \mathrm{nmol} / \mathrm{L}$ & $1.4-14.3 \mathrm{nmol} / \mathrm{L}$ \\
\hline Testosterone & $1.5 \mathrm{nmol} / \mathrm{L}$ & $0.3-1.7 \mathrm{nmol} / \mathrm{L}$ \\
\hline Cortisol following ODST & $17 \mathrm{nmol} / \mathrm{L}$ & $<50 \mathrm{nmol} / \mathrm{L}$ following ODST \\
\hline 17-hydroxyprogesterone & $1.3 \mathrm{nmol} / \mathrm{L}$ & $0-5 \mathrm{nmol} / \mathrm{L}$ \\
\hline Prolactin & $183 \mathrm{~m} \mathrm{IU} / \mathrm{L}$ & $102-496 \mathrm{~m} \mathrm{IU} / \mathrm{L}$ \\
\hline LH & $4.9 \mathrm{IU} / \mathrm{L}$ & \\
\hline FSH & $7.4 \mathrm{IU} / \mathrm{L}$ & \\
\hline ACTH & $16 \mathrm{ng} / \mathrm{L}$ & <50 ng/L@0900 \\
\hline TSH & $1.5 \mathrm{~m} \mathrm{U} / \mathrm{L}$ & $0.27-4.2 \mathrm{~m} \mathrm{U} / \mathrm{L}$ \\
\hline Progesterone & $10.9 \mathrm{nmol} / \mathrm{L}$ & \\
\hline
\end{tabular}

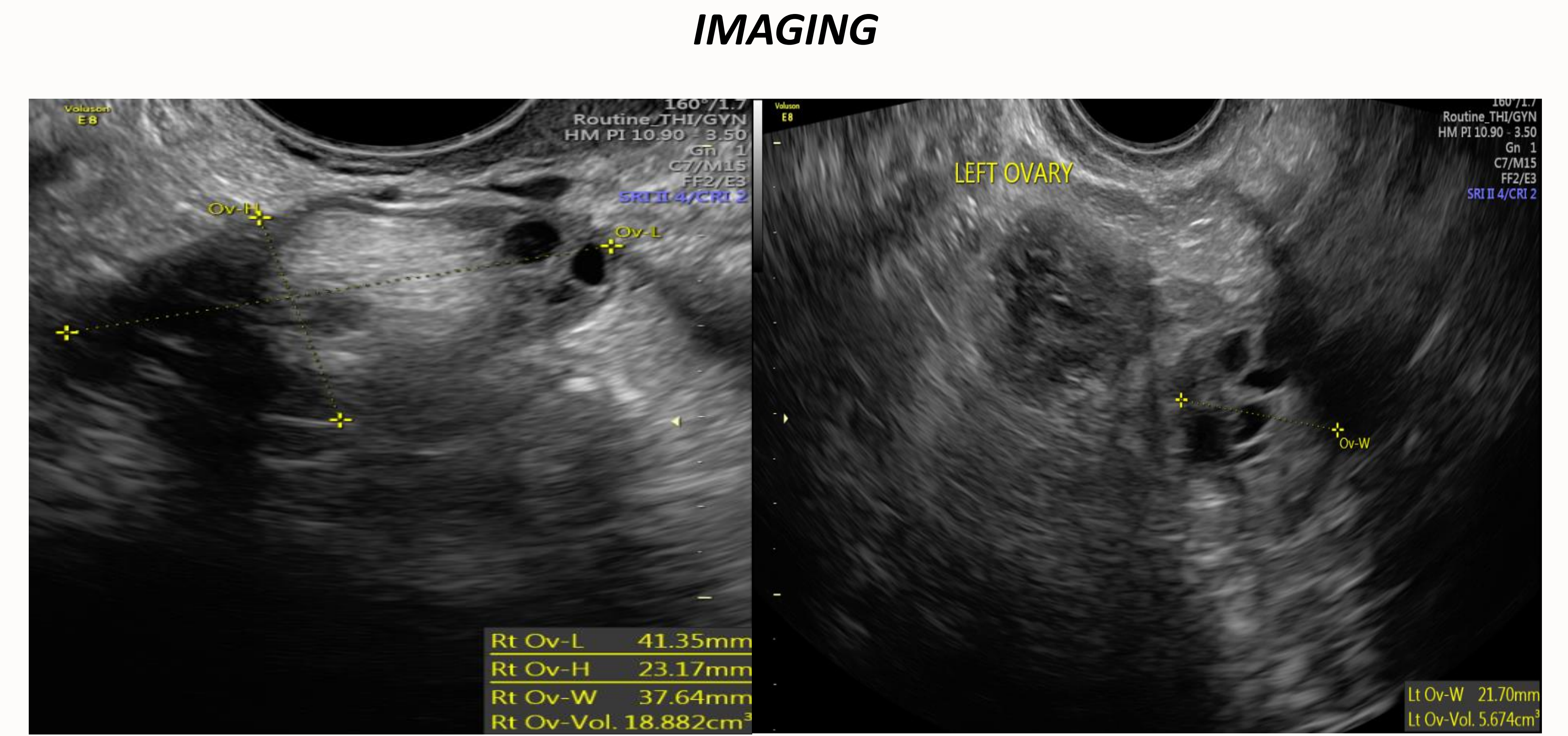

A transvaginal US did not demonstrate any features typical of polycystic ovaries and an endometrial thickness of $4 \mathrm{~mm}$.

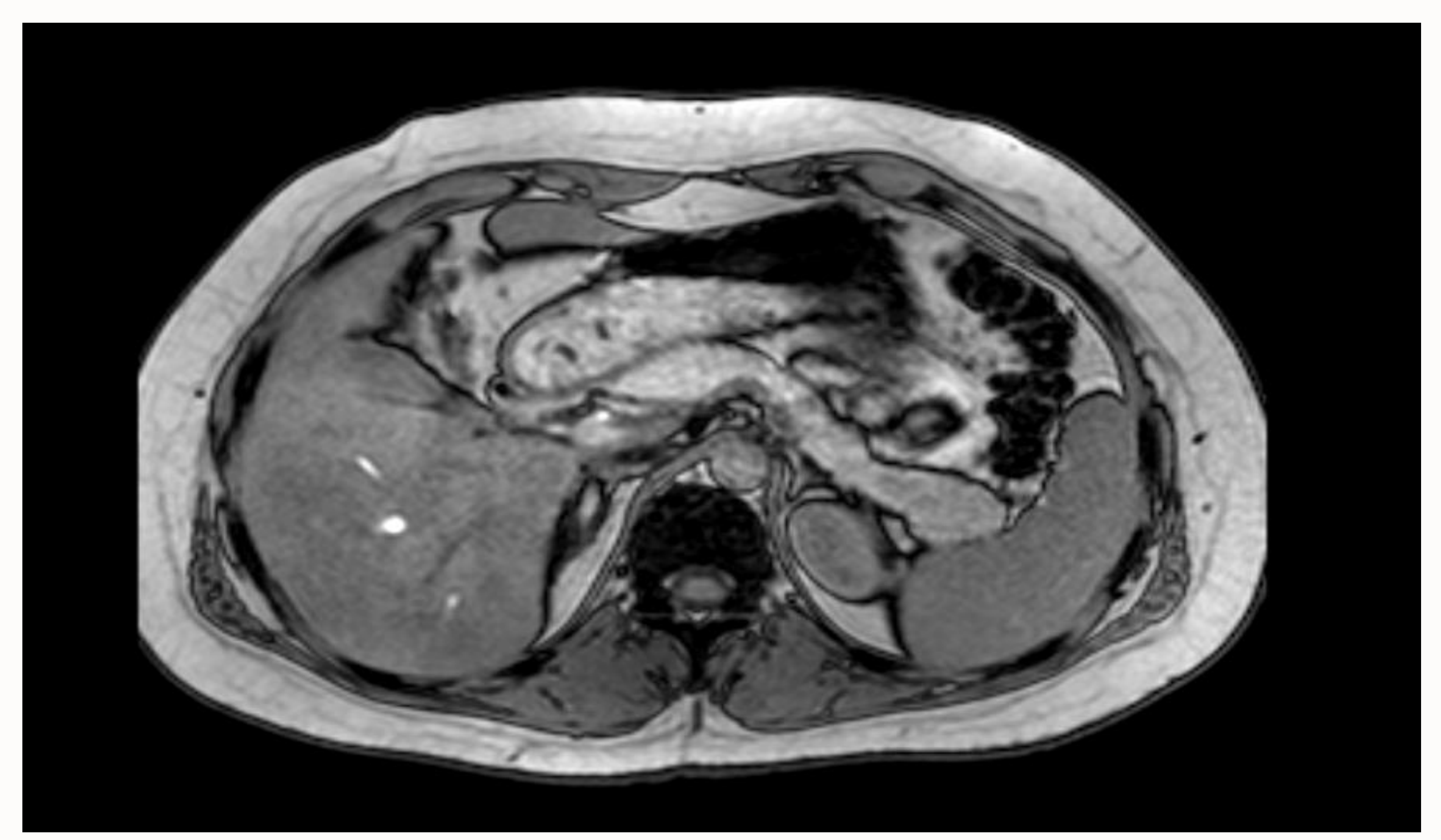

A dedicated MRI of adrenals glands did not demonstrate any pathology.

\section{DISCUSSION}

The above case illustrates a challenging case of elevated DHEAS causing hirsutism and oligomenorrhea but no adrenal or ovarian pathology identified on imaging. Radetti et al describe a similar case of isolated DHEAS elevation in a 17-year-old male ${ }^{2}$. We recommend that idiopathic elevation in DHEAS should be considered as a rare differential for hirsutism and oligomenorrhea in women.

\section{REFERENCES}

1. Owen K, Wass J. Oxford Handbook of Endocrinology and Diabetes. 3rd edition. Oxford: Oxford University Press, 2014

2. Radetti G, Cacciari E, Zachmann M. Isolated dehydroepiandrosterone sulphate hypersecretion: a case report. Eur J Pediatr. 1990 Aug;149(11):762-4.

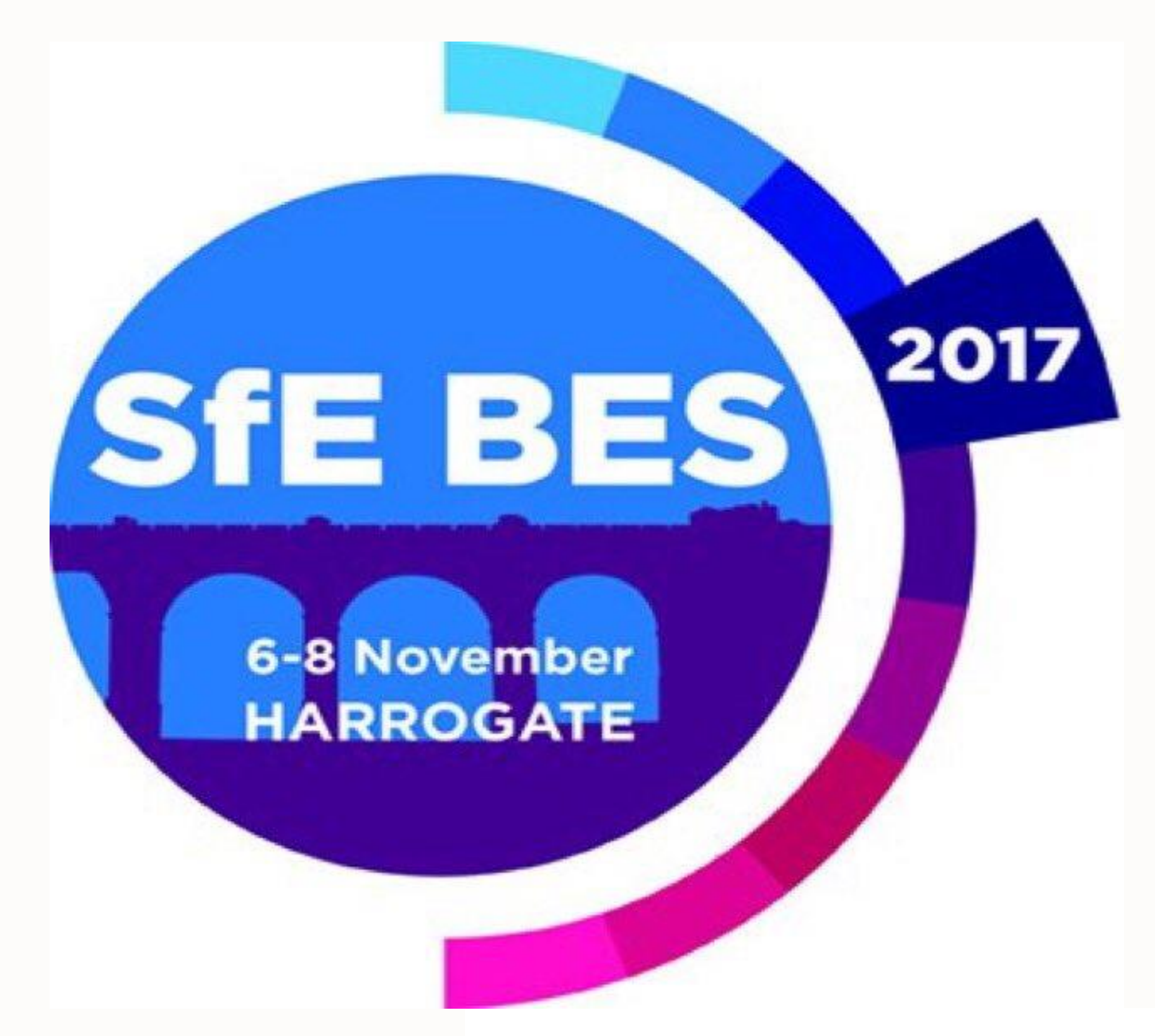

